\title{
Correction to: Long-term follow-up results of medial opening wedge high tibia osteotomy with a pre-countered non-locking steel plate
}

\author{
Simo S. A. Miettinen ${ }^{1,2}\left(\mathbb{D} \cdot\right.$ Hannu J. A. Miettinen ${ }^{1} \cdot J_{\text {Jssi Jalkanen }}{ }^{1} \cdot$ Antti Joukainen $^{1} \cdot$ Heikki Kröger $^{1,2}$
}

Published online: 28 June 2021

(c) The Author(s) 2021

\section{Correction to: Archives of Orthopaedic and Trauma Surgery https://doi.org/10.1007/s00402-021-03927-8}

The original version of this article unfortunately contained a mistake. Figures 5 and 6 captions were interchanged.

The corrected captions with figures are given in the following page.

1 Department of Orthopaedics, Traumatology, and Hand Surgery, Kuopio University Hospital, P.O. Box 1777, 70211 Kuopio, Finland

2 Faculty of Health Sciences, University of Eastern Finland, Yliopistonranta 1, 70210 Kuopio, Finland 


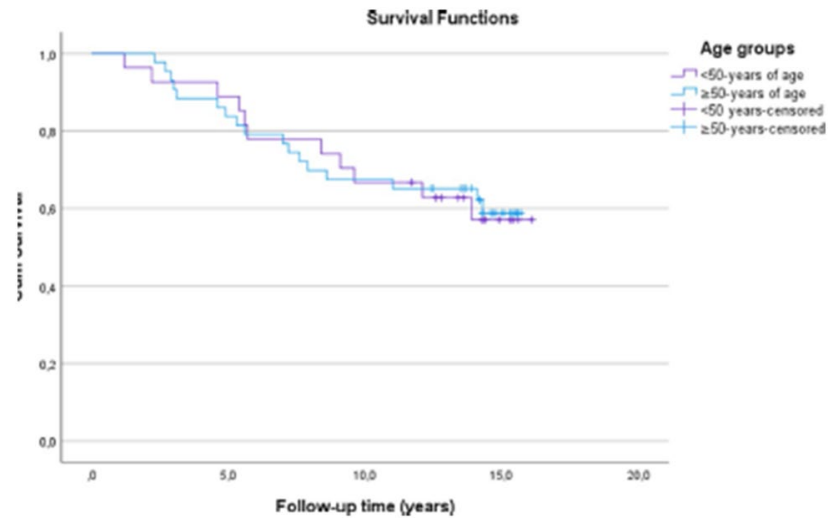

Fig. 5 Kaplan-Meier survival analysis of time. The estimates for the cumulative survival with no need for total knee arthroplasty conversion after medial open wedge high tibia osteotomy for patients $<50$-years was $89 \%$ at 5 -years, $67 \%$ at 10 -years and $57 \%$ at 16.1-years (SE 1.0, CI 95\% 10.5-14.3) and for patients $\geq 50$-years it was $84 \%$ at 5 -years, $67 \%$ at 10 -years and $59 \%$ at 15.7 years (SE 0.8, CI 95\% 10.6-13.6). Log-rank test, $p=0.93$

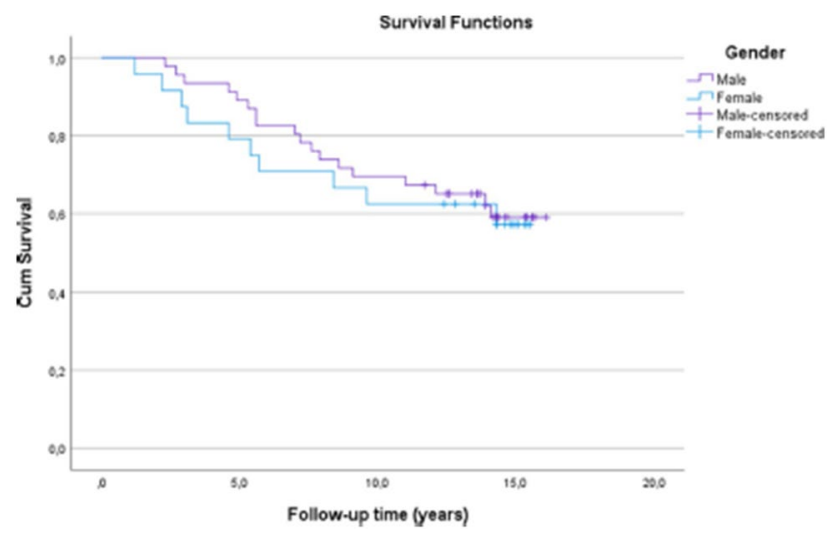

Fig. 6 Kaplan-Meier survival analysis of time. The estimates for the cumulative survival with no need for total knee arthroplasty conversion after medial open wedge high tibia osteotomy for females was $79 \%$ at 5 -years, $63 \%$ at 10 -years and $57 \%$ at 15.5 years (SE 1.1, CI 95\% 9.3-13.6) and for males it was $89 \%$ at 5-years, $70 \%$ at 10 -years and 59\% at 16.1-years (SE 0.7, CI 95\% 11.3-14.0). Log-rank test, $p=0.76$
Open Access This article is licensed under a Creative Commons Attribution 4.0 International License, which permits use, sharing, adaptation, distribution and reproduction in any medium or format, as long as you give appropriate credit to the original author(s) and the source, provide a link to the Creative Commons licence, and indicate if changes were made. The images or other third party material in this article are included in the article's Creative Commons licence, unless indicated otherwise in a credit line to the material. If material is not included in the article's Creative Commons licence and your intended use is not permitted by statutory regulation or exceeds the permitted use, you will need to obtain permission directly from the copyright holder. To view a copy of this licence, visit http://creativecommons.org/licenses/by/4.0/.

Publisher's Note Springer Nature remains neutral with regard to jurisdictional claims in published maps and institutional affiliations. 